Submission ID: 43894

\title{
Experimental Investigation of Gas Filtration of Hydrate-Saturated
}

Sediments

E.M. Chuvilin (Skoltech, MSU), B.A. Bukhanov* (Skolkovo Institute of Science and Technology), S.I. Grebenkin (Moscow State University), V.A. Istomin (VNIIGAZ, MSU), A. Okwananke (Heriot-Watt University), J. Yang (Heriot-Watt University), B. Tohidi (Heriot-Watt University)

\section{SUMMARY}

The experimental investigation of gas permeation of sandy sediments during increasing of gradient pressure was carried out in the conditions before and after pore hydrate accumulation. The results show that there are permeability changes caused by gradient pressure increasing, due to various structural and texture transformations. The permeability increasing was noted by increasing of the differential pressure (more than $0.2 \mathrm{MPa}$ ) associated with the partial pore space destruction (gas fracturing) and the formation of microcracks. In the process of gas filtration through hydrate-bearing sediments the permeability is decreasing with increasing differential pressure, which may be due to additional hydrate formation processes in the porous media. Thus, experimental investigations that the gas filtration of gas through hydrate-saturated cores is accompanied by a number of physical and chemical processes that should be taken into account during methane production from gas and gas hydrate deposits. 
Экспериментальное изучение фильтрации газа в гидратосодержащих породах

Е.М Чувилин (Сколтех, МГУ), Б.А. Буханов* (Сколтех), С.И. Гребенкин (МГУ), В.А. Истомин (ВНИИГаз, Сколтех), А. Оквананк (Хериот-Ватт), Дж. Йанг (Хериот-Ватт), Б. Тохиди (ХериотВатт)

\section{Введение}

За последние несколько десятилетий в мире существенно возрос интерес к природным газовым гидратам как к потенциальному источнику углеводородов [1]. За этот период были проведены серьезные экспериментальные исследования и пилотные полевые проекты в области разработки технологий добычи природного газа из гидратосодержащих скоплений. На сегодняшний день разработаны следующие основные технологические подходы к добыче гидратного газа: снижение давления в залежи с целью разложения газогидратов в пласте, термическое воздействие на газогидратный пласт, ввод ингибиторов для разрушения газогидратных образований, тепловое воздействие на призабойную зону пласта, а также сочетание этих методов [2].

В настоящее время возникает необходимость создания корректной прогнозной модели и создания симуляторов добычи метана из природных гидратосодержащих коллекторов. При этом одной из наиболее важных характеристик является проницаемость по газу гидратосодержащего коллектора [3]. На сегодняшний день существуют технические трудности, связанные с измерением проницаемости природных гидратосодержащих кернов, поскольку при их отборе и подъеме на поверхность поровые гидраты могут частично разлагаться. Поэтому измеренные значения газовой проницаемости по керну могут существенно отличаться от истинной проницаемости гидратосодержащих коллекторов in-situ. В этой связи представляется актуальным проведение специальных исследований по изучению газовой проницаемости и процессов, протекающих при фильтрации газа в породахколлекторах с различной гидратонасыщенностью.

\section{Методика экспериментальных исследований}

Эксперименты по изучению фильтрации газа в гидратосодержащих дисперсных породах проводились на специальной фильтрационной установке, рассчитанной на давление газа до 35 МПа и температуры до $-5{ }^{\circ} \mathrm{C}$ (рис. 1).

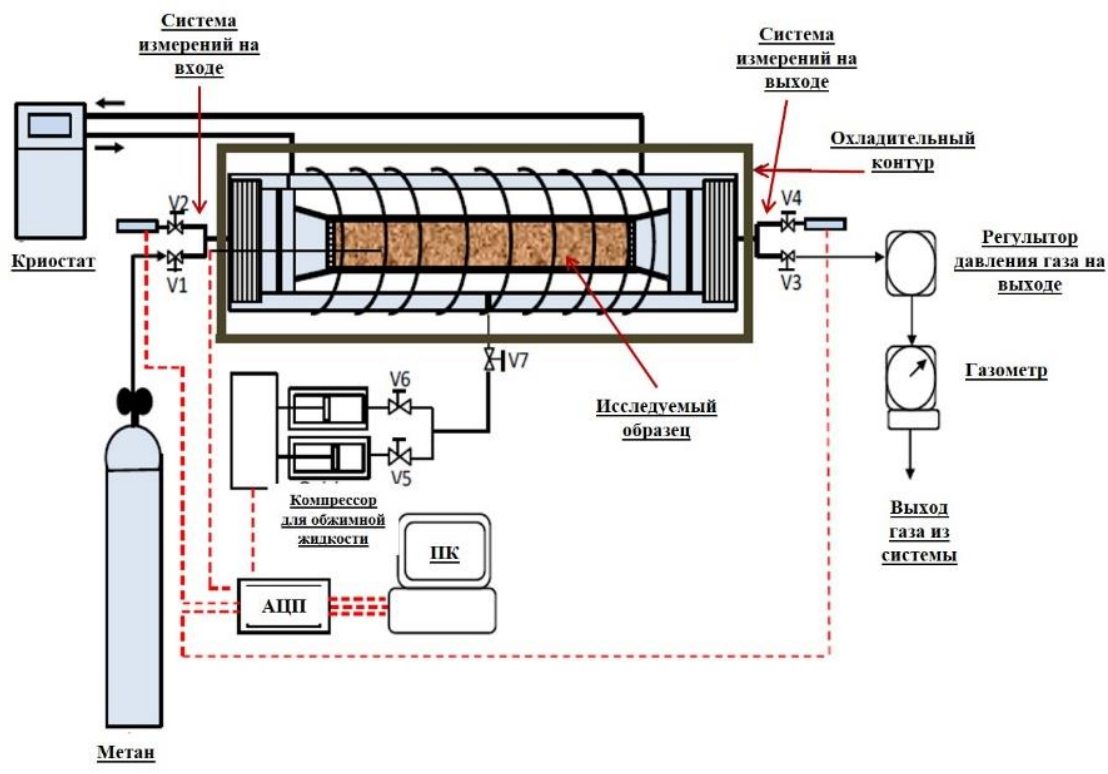

Рис. 1. Схема фильтрационной установки для исследования фильтрации газа и оценки газопроницаемости в гидратосодержащих породах. Красными пунктирными линиями отмечены информационные каналы, а черными линиями отмечена система подачи газа и жидкости (охлаждающей и обжимной). 
Основным элементом данной установки является кернодержатель, внутрь которого в специальной резиновой оболочке помещается исследуемый образец цилиндрической формы (диаметр 40 мм, высота 155 мм). Керн зажимается между двух металлических цилиндров с отверстиями для поддержания равномерного газового потока внутри дисперсной породы. С наружи образец, находящийся в резиновой оболочке, обжимается гидравлической жидкостью для сохранения образцом правильной цилиндрической формы, а также для минимизации проскальзывания газа между керном и резиновой оболочкой в процессе продувки. На входе и на выходе к кернодержателю установлена система регистрации давления газа. На выходе дополнительно установлен регулятор выходного давления.

Для выполненной серии экспериментов давление на выходе было всегда постоянным и составляло 3,45 МПа. Кернодержатель с системой подводящих трубок помещался в емкости с охлаждающей жидкостью, температурный режим которой регулировался термостатом. Все представленные эксперименты проводились при низкой положительной температуре $\sim 0,2{ }^{\circ} \mathrm{C}$. В качестве газа-гидратообразователя использовался чистый метан $(99,999 \%)$, а объекты исследования - рыхлые песчаные породы, представленные мелкозернистым песком (содержание фракции 0,15-0,35 мм достигает 65\%), в минеральном составе которого преобладает кварц (более 97\%) и смесью вышеуказанного песка с 5\% монтмориллонитовой глины $\left(\right.$ песок $+5 \%$ м/м). Начальная влагонасыщенность $\left(S_{\mathrm{w}}\right)$ образцов песчаных пород составляла $\sim 77 \%$, а пористость (n) $\sim 33 \%$. Также при исследовании фильтрации метана через гидратосодержащие породы использовались образцы кварцевого песчаника. Плотность скелета песчаника составляла 2,09 г/см3, а пористость (n) 18\%. Начальная влагонасыщенность образцов песчаника задавалась равной 56\%. Для исследуемых образцов пород изучение фильтрации метана проводилось до гидратонасыщения, когда большая часть пор была занята поровой водой, а также при гидратонасыщении, когда в поровом пространстве находился газогидрат, вода, а также свободный газ (метан).

Методика гидратонасыщения исследуемых образцов пород состояла в следующем: вначале при комнатной температуре $\left(+20{ }^{0} \mathrm{C}\right)$ влагонасыщенный дисперсный образец помещался в кернодержатель и задавалось начальное обжимное давление. Затем постепенно в образец (одновременно через входной и выходной цилиндр) подавался гидратообразующий газ $\left(\mathrm{CH}_{4}\right)$ до давления 3,5 МПа, при этом обжимное давление так же постепенно поднималось. В дальнейшем кернодержатель с образцом охлаждался до низких положительных температур $\sim 0,2{ }^{\circ} \mathrm{C}$. В этих термобарических условиях начинался процесс образования порового гидрата, окончание которого определялось по стабилизации давления газа. По завершению процесса гидратонакопления в образец подавалось избыточное газовое давление, система выстаивалась и затем впускной и выпускной клапана открывались и начиналась фильтрация газа через образец. Когда скорость потока газа на выходе стабилизировалось проводилась регистрация перепадов давления на торцах образца. Для расчета эффективного коэффициента газопроницаемости использовалось уравнение Дарси для осевого потока при стационарной фильтрации [4].

\section{Результаты и обсуждение}

В результате проведенных фильтрационных экспериментов было установлено, что для образцов песка без глинистых добавок характерно повышение эффективной проницаемости при увеличении разности давлений на концах образца (рис.2). Для чистого песка проницаемость при минимальном градиенте давлений (0,06 МПа) составляла 115 мД, а при увеличении дифференциального давления до 0,6-0,7 МПа, проницаемость выросла вдвое и составила 256,4 мД. В экспериментах с добавлением 5\% монтмориллонита наблюдалась обратная зависимость. С увеличением разности давлений проницаемость снижалась от 107 до 37 мД (рис. 2).

Полученные результаты указывают на качественное различие проницаемости песчаных пород в зависимости от наличия глинистой компоненты. Во влажных песчаных образцах без глинистых частиц фильтрация газа сопровождается отжатием и выносом поровой воды, что приводит к увеличению проницаемости. При наличии глинистой компоненты в песчаных 


\section{EAGE}

породах фильтрация газа сопровождается перераспределением не только поровой влаги, но и глинистых частиц, которые могут закупоривать поровое пространство (кольматация) и тем самым вызывать снижение газопроницаемости.

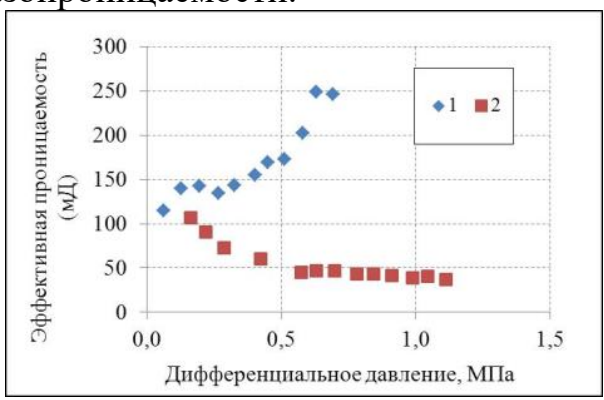

Рис.2. Влияние дифференциального давления на фильтрацию газа в песчаных влагосодержащих ( $\mathrm{Sw}=77 \%)$ образцах, не содержащих поровые гидраты $\left(\mathrm{t}=+4,0{ }^{\circ} \mathrm{C}\right)$.

1 - кварцевый песок, 2- кварцевый песок с добавлением 5\% монтмориллонитовой глины.

При оценке фильтрации газа через гидратосодержащие песчано-глинистые образцы было обнаружено резкое изменение газопроницаемости на начальной стадии увеличении градиента давления от 0,5 до $1 \mathrm{MПа} \mathrm{(рис.} \mathrm{3).}$

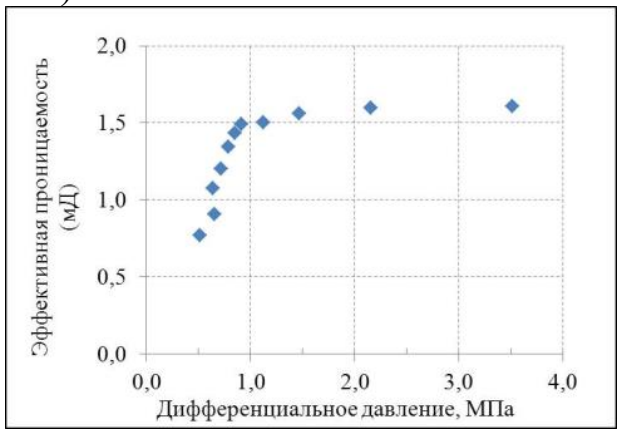

Рис. 3. Влияние дифференциального давления на изменение проницаемости по газу в гидратосодержащем песчано-глинистом образце (песок с добавлением 5\% монтмориллонита). Исходное гидратосодержание образца около $34 \%$.

При дальнейшем увеличении градиента давления газопроницаемость менялась незначительно. Отмеченное повышение фильтрации газа, по-видимому, связано с определёнными структурными преобразованиями порового пространства гидратосодержащего образца (газоразрыв) и формирование новых каналов фильтрации газа.

Исследование газопроницаемости до гидратообразования в сцементированных породах (кварцевых песчаниках) показало, что даже незначительное повышение градиента давления вызывает резкое увеличение газового потока, связанное с выносом поровой влаги из образца (рис.4).

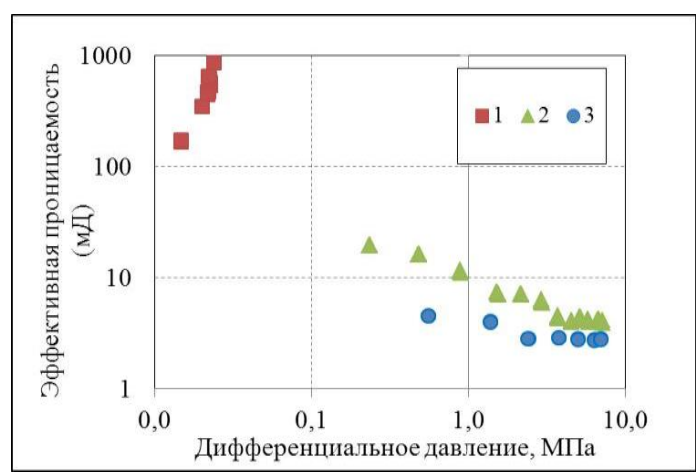

Рис. 4. Влияние дифференциального давления на изменение проницаемости по газу в образцах песчаников. 1- влагосодержащий без гидратов; 2 и 3 гидратосодержащие, с начальным гидратонасыщением 15 и 44\%, соответственно. 
Снижение газопроницаемости в гидратосодержащих образцах песчаника в условиях увеличения градиента давления обусловлено процессами дополнительного гидратообразования, которые могут активизироваться в условиях фильтрации гидратообразующего газа. Это подтверждается более активным снижением проницаемости в образце с меньшим начальным гидратосодержанием. Также существенным фактором, усиливающим дополнительное гидратообразование при фильтрации газа, может служить значительное понижение температуры, вызванное повышением градиента давления.

\section{Выводы}

Проведены экспериментальные исследования эффективной проницаемости по газу для песчаных пород до и после гидратонасыщения.

Для песчаных образцов, не содержащих газовые гидраты, показано принципиальное различие в зависимостях их проницаемости при увеличении градиента давления в случае наличия или отсутствия глинистых примесей. В первом случае фильтрация газа вызывает отжатие влаги и увеличение газопроницаемости. В песчаных образцах, содержащих глинистые примеси, перераспределение поровой влаги при фильтрации газа может сопровождаться кальматацией порового пространства, что снижает проницаемость.

При гидратонасыщении песчаных образцов наблюдается значительное снижение газовой проницаемости. На основе экспериментальных данных показано, что процесс фильтрации газа при повышенных дифференциальных давлений (более 0,2 МПа) может приводить к частичной деструкции порового пространства (газоразрыв) и образованию микро-каналов, которые будут существенно увеличивать проницаемость гидратосодержащих образцов. Также в ряде случаев в процессе фильтрации газа через гидратосодержащие породы может происходить дополнительное образование порового гидрата, что будет вызывать снижение проницаемости. Таким образом, экспериментальные исследования показали, что фильтрация газа через гидратонасыщенный керн сопровождается рядом физико-химических процессов, которые следует учитывать при разработке газогидратных залежей.

\section{Благодарности}

Исследования выполнены при сотрудничестве Сколковского Института Науки и Технологии и университета Хериот-Ватт (Великобритания) и частичной поддержки РНФ (грант № 16-1700051).

\section{Литература}

[1] Max M.D., Johnson A.H. Exploration and Production of Oceanic Natural Gas Hydrate. Springer. 2016. Doi: 10.1007/978-3-319-43385-1

[2] Yang J., Okwananke A., Tohidi B., Chuvilin E., Maerle K., Istomin V., Bukhanov B., Cheremisin A. Flue gas injection into gas hydrate reservoirs for methane recovery and $\mathrm{CO}_{2}$ sequestration. Energy Conversion and Management. 2017, 136, 431-438

[3] Kleinberg R.L., Flaum C., Griffin D.D., Brewer P.G., Malby G.E., Peltzer E.T. et al., Deep sea NMR: Methane hydrate growth habit in porous media and its relationship to hydraulic permeability, deposit accumulation, and submarine slope stability. Journal of Geophysical Research: Solid Earth. 2003, EPM 12, 1-17

[4] Recommended Practices for Core Analysis, RP 40, $2^{\text {nd }}$ ed. American Petroleum Institute: Washington DC. 1998

\section{References}


[1] Max M.D., Johnson A.H. Exploration and Production of Oceanic Natural Gas Hydrate. Springer. 2016. Doi: 10.1007/978-3-319-43385-1

[2] Yang J., Okwananke A., Tohidi B., Chuvilin E., Maerle K., Istomin V., Bukhanov B., Cheremisin A. Flue gas injection into gas hydrate reservoirs for methane recovery and $\mathrm{CO} 2$ sequestration. Energy Conversion and Management. 2017, 136, 431-438

[3] Kleinberg R.L., Flaum C., Griffin D.D., Brewer P.G., Malby G.E., Peltzer E.T. et al., Deep sea NMR: Methane hydrate growth habit in porous media and its relationship to hydraulic permeability, deposit accumulation, and submarine slope stability. Journal of Geophysical Research: Solid Earth. 2003, EPM 12, 1-17

[4] Recommended Practices for Core Analysis, RP 40, 2nd ed. American Petroleum Institute: Washington DC. 1998 